\title{
Diary for women's joint disease (traditional and modern medicine): good or bad!
}

\section{Opinion}

Diseases of joints are known as complications of women. Rheumatism and arthritis are more common in women, because of higher prevalence of autoimmune disease in them. In addition to this, osteoporosis occurs in post-menopausal ages. ${ }^{1}$ So most of the patients going to rheumatologists are women. ${ }^{2}$ In such conditions, rheumatologists usually encourage them to use more diaries in particular milk and yogurt. ${ }^{3}$ Their reason is the calcium existing in diaries. ${ }^{4}$ On the other hand, the quadruple temperament-based traditional medicine is opposite to this. This traditional medicine is of the conviction that diaries in general and yogurt and yogurt-drink in particular are phlegmatic. Phlegm is the temporary of wetness and coldness. Phlegmatic people are usually fat and seem white and babyface. Hence most of them are women. ${ }^{5,6}$ The common point between the traditional and modern medicine is that both of them believe that such joint diseases get worse in exposing to moisture or living in underground. Thus joint and rheumatoid disease gets worse with higher levels of phlegm. Hereby the best solution seems to be using warm herbs such as angelica and pennyroyal with yogurt and yogurtdrink as well as using banana with milk. Original researches in this field are needed.

\section{Acknowledgements}

None.

\section{Conflict of interest}

The author declares no conflict of interest.

\section{References}

1. Singh R, Kumari G. Study of lower limb neuromuscular characteristics in postmenopausal women with osteoarthritis. Asian Journal of Biomedical and Pharmaceutical Sciences. 2016;6(52):28-30.

2. Thyberg I, Dahlström Ö, Björk M, et al. Hand pains in women and men in early rheumatoid arthritis, a one year follow-up after diagnosis. The Swedish TIRA project. Disabil Rehabil. 2016;11:1-10.
Volume 2 Issue 4 - 2016

\author{
Seyyed Amir Yasin Ahmadi \\ Lorestan University of Medical Sciences, Iran
}

Correspondence: Seyyed Amir YasinAhmadi, Student Research Committee, Lorestan University of Medical Sciences, Khorramabad, Iran, Tel +989392838309, Email yasin_ahmadi73@yahoo.com

Received:September 08, 2016 | Published: September 19, 2016

3. Rohmah RN, Widjajanto E, Fatchiyah F. Microvilli microstructure and inflammatory mechanism of rat (Rattusnorvegicus) ileum on rheumatoid arthritis model prove by CSN1S2 proteins of goat Ethawah breed milk 2 and Yogurt 3. Asian pacific journal of tropical disease. 2015;5(7):564 568.

4. Provan SA, Olsen IC, Austad C, et al. Calcium supplementation and inflammation increase mortality in rheumatoid arthritis: A 15-year cohort study in 609 patients from the Oslo rheumatoid arthritis register. Semin Arthritis Rheum. 2017;46(4):411-417.

5. Mojahedi M, Naseri M, Majdzadeh R, et al. Reliability and validity assessment of Mizaj questionnaire: a novel self-report scale in Iranian traditional medicine. Iran Red Crescent Med J. 2014;16(3):e15924.

6. Behmanesh E, Mojahedi M, Saghebi R, et al. Comparison between the "Theory of Arkan"(Four Elements) in traditional persian medicine and the "Theory of Five Elements" in traditional Chinese medicine. Journal of Research on History of Medicine. 2015;4(2):1-4. 